\title{
Degradability of organic-inorganic cellulose acetate butyrate hybrids in sea water
}

\author{
Patrycja Wojciechowska $^{1^{*}}$, Aleksandra Heimowska ${ }^{2}$, Zenon Foltynowicz ${ }^{3}$, Maria Rutkowska ${ }^{4}$ \\ ${ }^{1}$ Poznań University of Economics, Department of Industrial Commodity Science, al. Niepodległości 10, 61-875 Poznań, \\ Poland, e-mail: p.wojciechowska@ue.poznan.pl \\ ${ }^{2}$ Gdynia Maritime University, Department of Chemistry and Industrial Commodity Science, \\ ul. Morska 83, 81-225 Gdynia, Poland, e-mail: halex1@wp.pl \\ ${ }^{3}$ Poznań University of Economics, Department of Product Ecology, al. Niepodległości 10, \\ 61-875 Poznań, Poland, e-mail: zenon.foltynowicz@ue.poznan.pl \\ ${ }^{4}$ Gdynia Maritime University, Department of Chemistry and Industrial Commodity Science, \\ ul. Morska 83, 81-225 Gdynia, Poland, e-mail: rutmaria@am.gdynia.pl \\ "Corresponding author: p.wojciechowska@ue.poznan.pl
}

\begin{abstract}
Environmental degradability of novel organic-inorganic cellulose acetate butyrate hybrids obtained via solgel process was investigated. The degradation of hybrids was studied under marine exposure conditions in the Baltic Sea for a period of 25 weeks. The influence of characteristic parameters of sea water on the degree of degradation monitored by changes of weight and optical microscopy was discussed. The degraded samples were also examined by FT-IR spectroscopy. It has been established that the $\mathrm{CAB} /$ silica hybrids are more susceptible to biodegradation in sea water environment than pure cellulose acetate butyrate.
\end{abstract}

Keywords: degradation, cellulose acetate butyrate, organic-inorganic hybrids, sea water.

\section{INTRODUCTION}

Rapid changes in public legislation caused by growing environmental pollution problem brought about considerable research interest in the design and development of new environmentally friendly materials which are one of the available options for the plastic waste disposal problem. Recent trends towards biodegradable materials have been focusing on the use of natural biopolymers like cellulose and starch. These materials offer several advantages: they are low cost, abundant and available from renewable resources. However, they have also some limitations like poor processability or high water absorbency. Therefore, cellulose esters seem to be an interesting alterative for the production of environmentally friendly materials ${ }^{1}$. Cellulose acetate butyrate $(\mathrm{CAB})$ is a thermoplastic polymer that has good mechanical properties, can be readily processed and is also susceptible to biodegradation ${ }^{2}$. There are numerous reports in the literature associated with polymer blends based on cellulose derivatives, however, there are only few which describe materials based on $\mathrm{CAB}$ and their susceptibility to biodegradation $^{2-6}$. So far, no information about the effect of silica incorporation into $\mathrm{CAB}$ matrix on the degradation of the material has previously been available. In this work, for the first time, we discuss the susceptibility to biodegradation of cellulose acetate butyrate organic-inorganic hybrids in comparison with pure $\mathrm{CAB}$.

In our study we used a novel hybrid material, obtained via sol-gel processing, which combines two components: organic polymer (CAB) and inorganic solid (silica particles). Hybrid materials, due to their unique properties, are promising systems with potential application in coatings, membranes, biomaterials, sensors and catalysis ${ }^{7-10}$. They open new possibilities of tailoring materials with improved mechanical and chemical properties, desirable toughness as well as elasticity comparing to pure organic polymers $^{11-15}$. Sol-gel processing is one of the most ef- ficient methods for preparation of hybrid materials. This technique comprises an initial hydrolysis of metal alkoxides and subsequent condensation reactions, resulting in metal oxides. The most commonly used precursor, which yields a silica network, is tetraethoxysilane (TEOS). The main advantages of sol-gel processing are mild conditions, i.e. low reaction temperature, and ease of control ${ }^{11,16}$.

The aim of this work was to investigate the susceptibility to biodegradation of cellulose acetate butyrate organicinorganic hybrids in the Baltic Sea water environment. We have examined the effect on degradation of two plasticizers: conventional diethyl phthalate (DEP) and biodegradable tributyl citrate (TBC). The degradation process was studied by determination of weight changes, chemical changes (ATR-FTIR) as well as by macro- and microscopic observation of samples surface.

\section{EXPERIMENTAL}

\section{Materials}

Cellulose acetate butyrate $(\mathrm{Mn}=70000$, containing 12-15 wt.\% acetyl, 1.2-2.2 wt.\% hydroxyl, 35-39 wt.\% butyryl) and TEOS (98\%) were supplied by Sigma Aldrich. Diethyl phthalate (DEP) and tributyl citrate (TBC) used as plasticizers were purchased from $\mathrm{POCH}$ and Fluka, respectively. Hydrochloric acid $(\mathrm{HCl} 35-38 \%)$ and acetone were supplied by $\mathrm{POCH}$ and used as received.

\section{Hybrid preparation}

Organic-inorganic hybrids based on cellulose acetate butyrate $(\mathrm{CAB})$ were synthesized according to the procedure we described in detail in Patent Pending (Polish Patent Office) ${ }^{\mathbf{1 7}}$. The samples compositions and codes are presented in Table 1. In the typical preparation of hybrids polymer $(\mathrm{CAB})$ was dissolved in acetone at room temperature, followed by plasticizer and TEOS addition and mixed vigorously using magnetic stirrer. Afterwards, cata- 
lytic amount of hydrochloric acid solution was added to initiate the sol-gel process. The homogenous solution was cast on a PTFE dish and left exposed to atmospheric conditions at room temperature followed by drying in a vacuum drier to ensure complete evaporation of acetone ${ }^{\mathbf{1 8}}$. Samples of pure CAB and polymer with $25 \%$ of plasticizer: diethyl phthalate (DEP) and tributyl citrate (TBC) were also prepared as a reference material.

Table 1. Sample compositions and codes

\begin{tabular}{|l|c|c|c|}
\hline $\begin{array}{l}\text { Sample } \\
\text { code }\end{array}$ & $\begin{array}{c}\text { Polymer/TEOS } \\
\text { (wt. ratio) }\end{array}$ & $\begin{array}{c}\text { DEP content } \\
(\%)\end{array}$ & $\begin{array}{c}\text { TBC content } \\
(\%)\end{array}$ \\
\hline CAB & - & - & - \\
\hline CAB DEP & - & 25 & - \\
\hline CAB6 DEP & $93.75 / 6.25$ & 25 & - \\
\hline $\begin{array}{l}\text { CAB12 } \\
\text { DEP }\end{array}$ & $87.5 / 12.5$ & 25 & - \\
\hline CAB TBC & - & - & 25 \\
\hline CAB6 TBC & $93.75 / 6.25$ & - & 25 \\
\hline $\begin{array}{l}\text { CAB12 } \\
\text { TBC }\end{array}$ & $87.5 / 12.5$ & - & 25 \\
\hline
\end{tabular}

\section{Environment}

The incubation of cellulose acetate butyrate hybrids took place in the Baltic Sea water in Gdynia Harbour. The samples were cut into 15 × $20 \mathrm{~mm}$ rectangles and located in a special galvanized sheet basket at $2 \mathrm{~m}$ depth under the sea surface, near the ship of the Polish Ship Salvage Company. The incubation of polymer samples in sea water lasted 25 weeks. After incubation the samples were taken out from the environment, washed thoroughly with distilled water and dried at room temperature to a constant weight.

\section{Methods}

\section{Macroscopic observation}

Macroscopic observation of hybrids surface changes during degradation was done using digital photo camera Casio QV2900UX.

\section{Optical microscopy}

Microscopic observation was performed in transmission light with an optical microscope Nikon Alphaphot2YS2 connected with digital photo camera Casio QV2900UX, at magnification 1:350.

\section{Changes in weight}

The weight changes of the degraded samples (\%) were determined using an electronic balance Gibertini E 42s, comparing with mass of undegraded samples before incubation. In a typical experiment, at least 3-5 samples were taken out from the sea environment and the average weight was used.

\section{Mechanical properties}

Mechanical properties (tensile strength and elongation at break) of the samples before incubation were investigated using a universal tensile machine (Instron 5565) with sample films $150 \mathrm{~mm}$ in length and $10 \mathrm{~mm}$ in width and at a crosshead speed of $100 \mathrm{~mm} / \mathrm{min}$ at room temperature (according to the test method described in International Standards PN-EN ISO 527-1:1998, PN-EN ISO3:1998). At least five tests were performed for each type of the sample, to ensure the reliability of the test results, and the average was used.

\section{The FT-IR spectra}

The FT-IR spectra were recorded on PerkinElmer, Spectrum 100 FT-IR spectrometer using ATR (attenuated total reflection) technique, over a range of $400-4000 \mathrm{~cm}^{-1}$.

\section{RESULTS AND DISCUSSION}

\section{Degradation environment}

The characteristic parameters of sea water according to the Institute of Meteorology and Water Management in Gdynia, Poland are presented in Table 2.

Table 2. The characteristic parameters of the Baltic Sea water

\begin{tabular}{|l|c|}
\hline Parameter & Period: April - September \\
\hline Temperature $\left({ }^{\circ} \mathrm{C}\right)$ & $7.2-20.1$ \\
\hline $\mathrm{pH}$ & $8.2-8.5$ \\
\hline $\mathrm{O}_{2}$ content $\left(\mathrm{cm}^{3} / \mathrm{dm}^{3}\right)$ & $6.5-10.0$ \\
\hline $\mathrm{Cl}^{-}$content $(\mathrm{g} / \mathrm{kg})$ & $3.3-3.6$ \\
\hline Salinity $(\mathrm{ppt})$ & $6.1-6.5$ \\
\hline
\end{tabular}

It is known that the abiotic parameters of sea water (temperature, $\mathrm{pH}$, salinity and oxygen content) have a significant influence on the development of living microorganisms in natural environment. Taking into consideration the characteristic parameters of the Baltic Sea water (Table 2) we can state that the temperature of sea water during the experiment $\left(7.2-20.1^{\circ} \mathrm{C}\right)$ was lower than preferred for enzymatic degradation which is in the range of $20-60^{\circ} \mathrm{C}^{\mathbf{1 9}}$. The value of $\mathrm{pH}$ in sea water was alkaline (8.2-8.5) on the stable level during the whole time of incubation, while the preferred $\mathrm{pH}$ for enzymatic degradation is in the range of $5-8^{19}$. We assume that low temperature of the Baltic Sea and slight alkalinity of the sea water could have had an influence on the development of psychrotrophic bacteria. In the first period of incubation, (April) we could observe lower temperatures $\left(7.2^{\circ} \mathrm{C}\right)$ and the highest oxygen content $\left(10 \mathrm{~cm}^{3} / \mathrm{dm}^{3}\right)$. These conditions have an influence on the activity of oxidizing enzymes. The situation was also favourable for development of aerobic epilithic bacteria. The metabolism of these microorganisms probably caused the decrease of oxygen content $\left(6.5 \mathrm{~cm}^{3} / \mathrm{dm}^{3}\right.$ in September $)$ and the changing concentration of carbon dioxide in sea water ${ }^{\mathbf{2 0}}$.

\section{Evaluation of the changes in samples during incubation in sea water}

The macroscopic observations of CAB samples surface are presented in Fig. 1. The changes of the surface of $\mathrm{CAB}$ samples obtained with DEP were more visible than for hybrids with TBC plasticizer. The brown areas on the surface of polymer samples are connected with living organisms in sea water, especially with the development of psychrotrophic bacteria ${ }^{21}$. The longer incubation time in sea water resulted in the bigger amount of brown areas on the samples surface.

The changes of surface morphology of the examined samples are shown in Fig. 2. The slight changes of the surface morphology were observed for the cellulose acetate butyrate. In contrast, $\mathrm{CAB} /$ silica hybrids showed the more distinct changes of surface morphology. We observed the correlation between the degree of degradation and the 


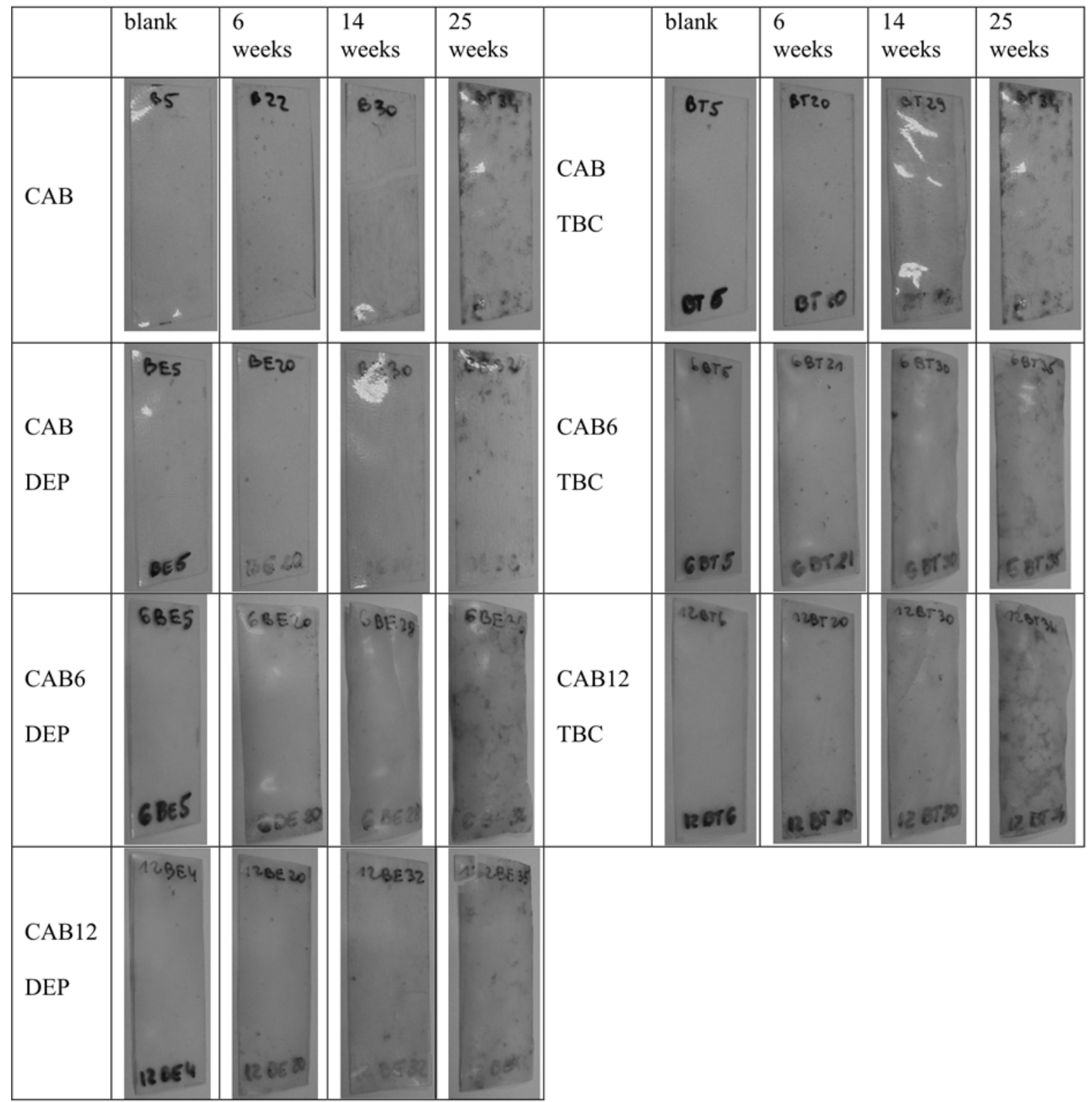

Figure 1. Macroscopic observations of $\mathrm{CAB}$ samples surface

amount of inorganic phase introduced into $\mathrm{CAB}$ matrix. The changes of surface morphology of CAB samples obtained with DEP were also more visible than for the samples with TBC. The dark places observed on the micrographs of the samples after the incubation in the Baltic Sea are connected with the presence of microorganisms from the microbiological active environment of the sea water ${ }^{22}$.

Figure 3 shows the periodical changes in the weight loss of the CAB sample films after the incubation in the sea water as a function of the incubation time.

The observation of the samples was confirmed by the results of their weight changes. The results of the degradation experiment showed that the organic-inorganic hybrids are more susceptible to environment conditions of the Baltic Sea than the pure cellulose acetate butyrate. The weight loss of pure CAB during the whole incubation time was not very significant $(1.9 \%)$ which is due to the chemical structure of this polymer. The degradation rate of $\mathrm{CAB}$ is slow because the substituents on the $\mathrm{CAB}$ (acetyl and butyryl groups) and steric hindrance prevent the microorganisms from destroying macrochains of cel- lulose. The same behaviour was also observed by Wang and co-workers ${ }^{6}$.

In our experiment the CAB samples behaved in a particular mode, depending on the amount of the inorganic phase incorporated into polymer matrix and on the type and amount of the plasticizer. In the hybrids with DEP plasticizer, the degradation process was proportional to the silica content (after 20 weeks of incubation CAB6 $\mathrm{DEP}=9.2 \%$; $\mathrm{CAB} 12 \mathrm{DEP}=12.2 \%$ ), but in the hybrids with TBC plasticizer we do not observe the same tendency $(\mathrm{CAB} 6 \mathrm{TBC}=7.9 \%$; $\mathrm{CAB} 12 \mathrm{TBC}=7.2 \%)$. The degradation dynamics and weight changes of samples with DEP plasticizer (CAB DEP, CAB6 DEP, CAB12 DEP) were more visible than for the samples with TBC plasticizer (CAB TBC, CAB6 TBC, CAB 12TBC). In the beginning, after 1 week of incubation in seawater, the decrease of weight for all CAB samples with DEP was very fast $(\mathrm{CAB} 6 \mathrm{DEP}=6 \%$; $\mathrm{CAB} 12 \mathrm{DEP}=5.1 \%)$, followed by almost constant value (CAB6 DEP $=5.4 \%$; $\mathrm{CAB} 12 \mathrm{DEP}=5.8 \%$ ) for the next 4 weeks. After 25 weeks of incubation in sea water organic-inorganic hybrids CAB6 DEP and CAB12 DEP lost respectively $17.3 \%$ and $17.9 \%$ 


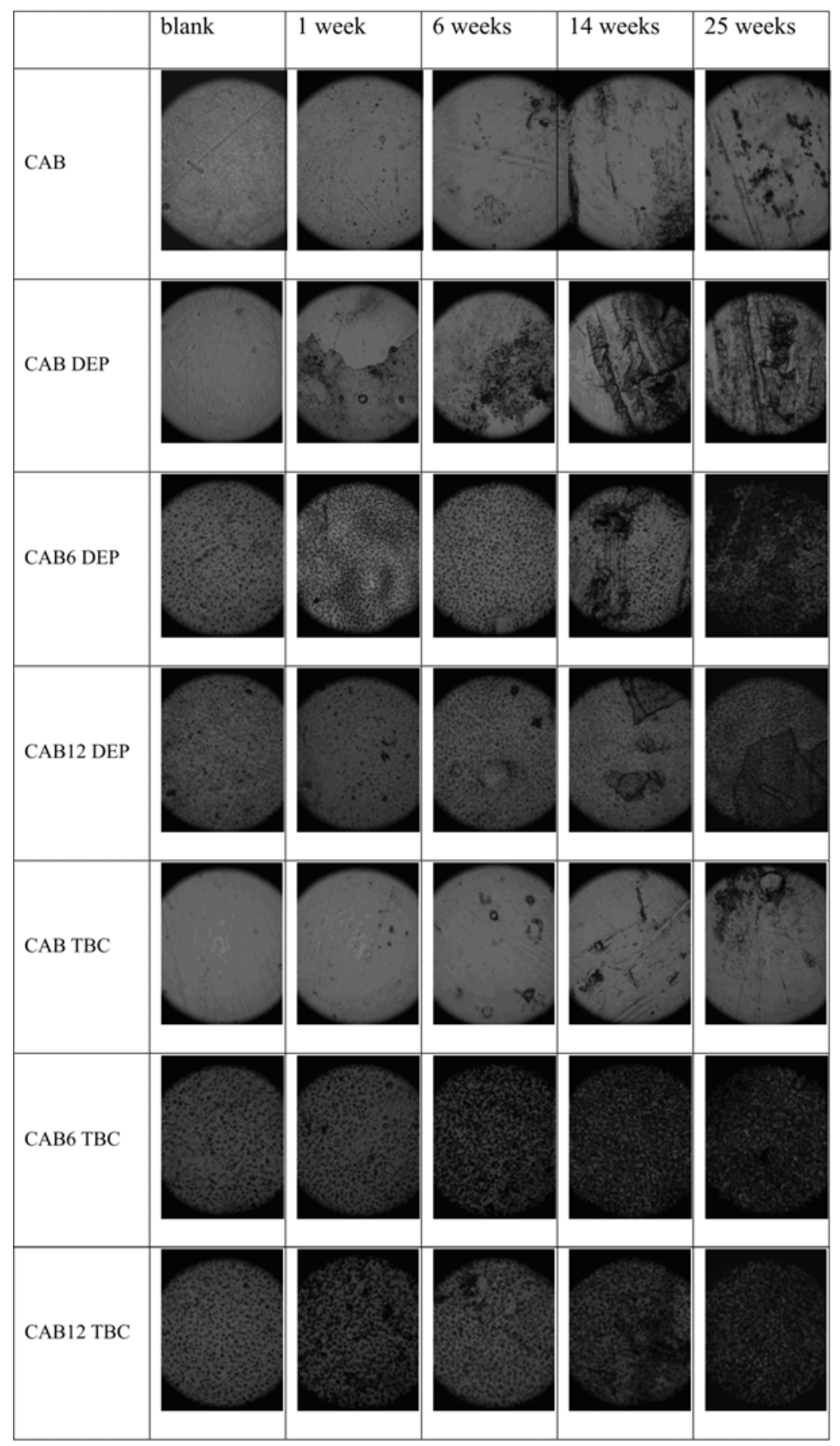

Figure 2. Microscopic observations of the $\mathrm{CAB}$ samples surface

of its weight, while $\mathrm{CAB}$ DEP sample (without silica) only $11.6 \%$. Investigation of the degradability of the $\mathrm{CAB}$ samples with TBC revealed slow, almost with the constant rate weight changes during the whole time of the experiment. The highest weight loss was observed for $\mathrm{CAB}$ TBC hybrid (9.3\%), while CAB6 TBC and CAB12 TBC were degraded in $7.9 \%$ and $7.2 \%$, respectively. The obtained results showed that both silica and the plasticizer play important roles in the degradation process of the samples. The addition of plasticizers to the pure $\mathrm{CAB}$ induces bigger changes in weight loss. This effect is amplified by the introduction of the inorganic phase into polymer matrix. Interestingly, the weight loss of the samples with DEP was more significant than of the samples with biodegradable TBC. We assume that this is due to the better plasticizing effectiveness of TBC (Fig. 4). The samples with DEP are more brittle and have higher tendency to

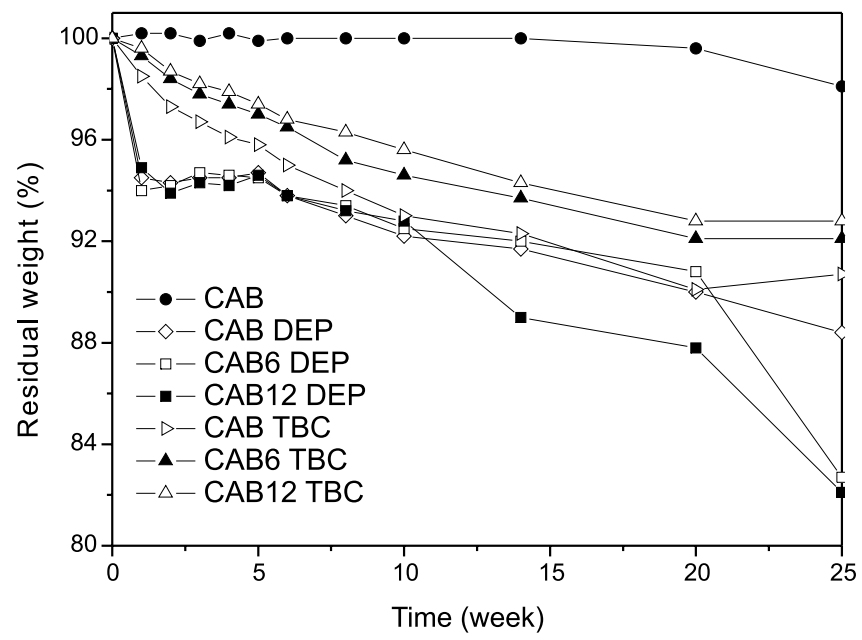

Figure 3. Weight losses of CAB, CAB DEP, CAB TBC and $\mathrm{CAB} /$ silica hybrids during the degradation process in the sea water 
a)

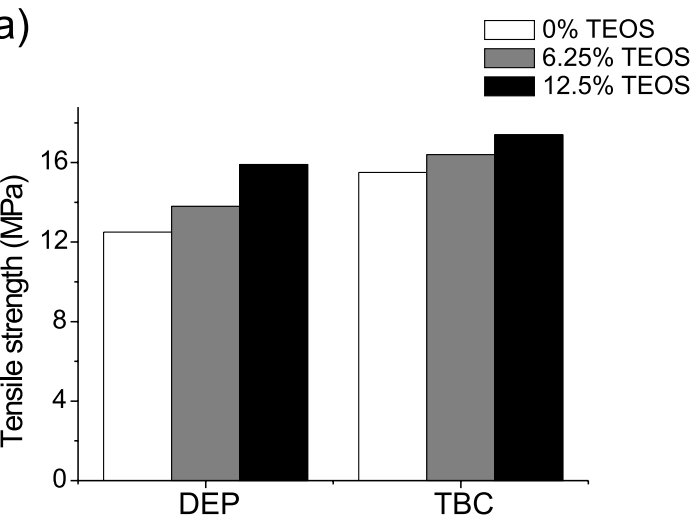

b)

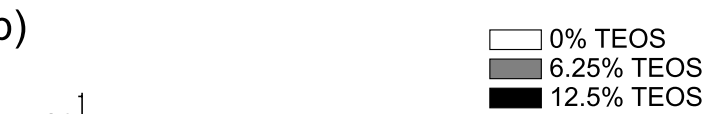

Figure 4. Comparison of mechanical properties of $\mathrm{CAB}$ and $\mathrm{CAB} /$ silica hybrids with $\mathrm{DEP}$ and $\mathrm{TBC}$ plasticizers

crack than the samples with TBC. Therefore, the higher weight losses of the DEP samples during the experiment in the dynamic sea water might also be induced by mechanical stress due to the natural movement of water. Hybrids with TBC show similar tensile strength to the samples with DEP, however the elongation at break is significantly higher in the case of TBC plasticized hybrids. Figure 4 shows the mechanical properties (tensile strength and elongation at break) of $\mathrm{CAB}$ and $\mathrm{CAB} /$ silica hybrids obtained with various amount of TEOS and two kinds of plasticizers: DEP and TBC. Taking into consideration these results and the observed weight changes we can conclude that the bigger stiffness and brittleness of the hybrids the higher weight loss during experiment. The results revealed also a synergistic effect of the silica phase which hinder the plastic flow and causes hardening and reinforcing of the polymer.

The analysis of ATR-FTIR spectra of the samples (Fig. 5-7) revealed practically no changes of the main bands $\left(1750 \mathrm{~cm}^{-1}(\mathrm{C}=\mathrm{O}), 1230 \mathrm{~cm}^{-1}\right.$ and $1170 \mathrm{~cm}^{-1}$ (C-O-C), $3500 \mathrm{~cm}^{-1}(\mathrm{OH})$ and $1050 \mathrm{~cm}^{-1}$ (stretching mode from the polymer backbone)) during the incubation period for pure $\mathrm{CAB}$, as well for all the organic-inorganic hybrids. This is due to the unchanged chemical structure of polymer, a major component of all CAB-hybrids, whose degradation is slow. These results indicate that enzymatic processes predominantly take place in the environmental degradation. The enzymatic degradation is only related to

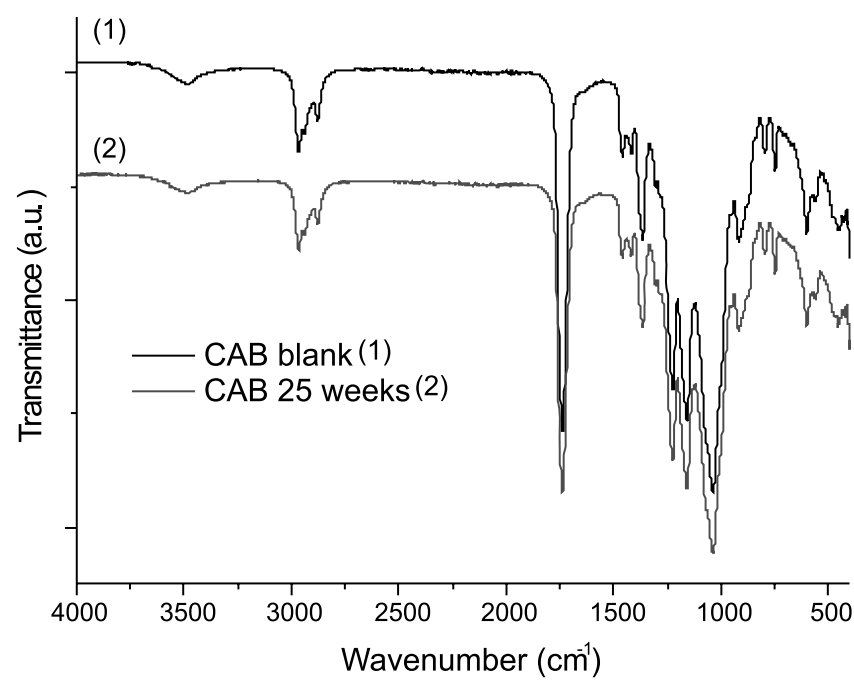

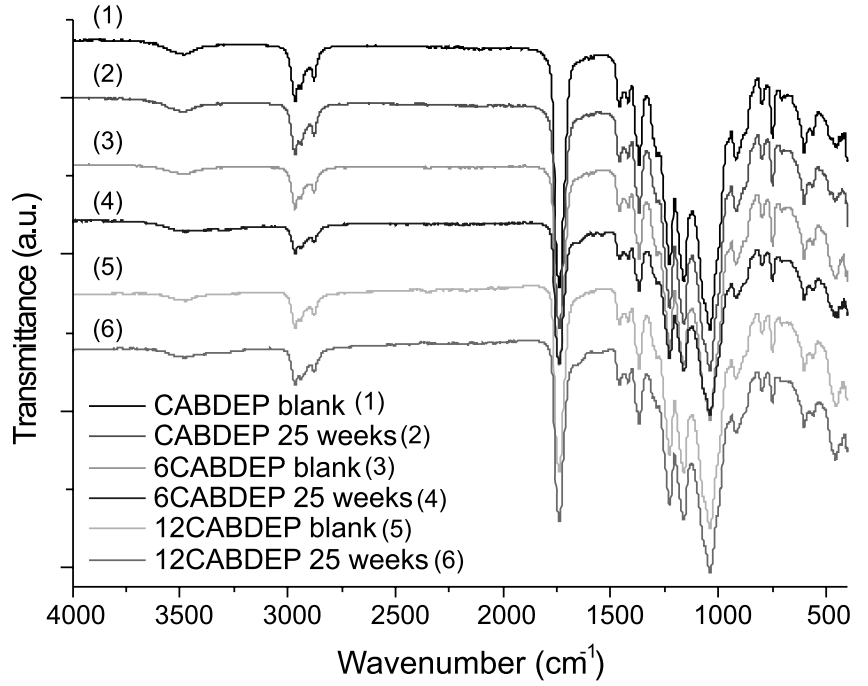

Figure 6. The ATR-FTIR spectra of CABDEP samples before and after the incubation in the sea water

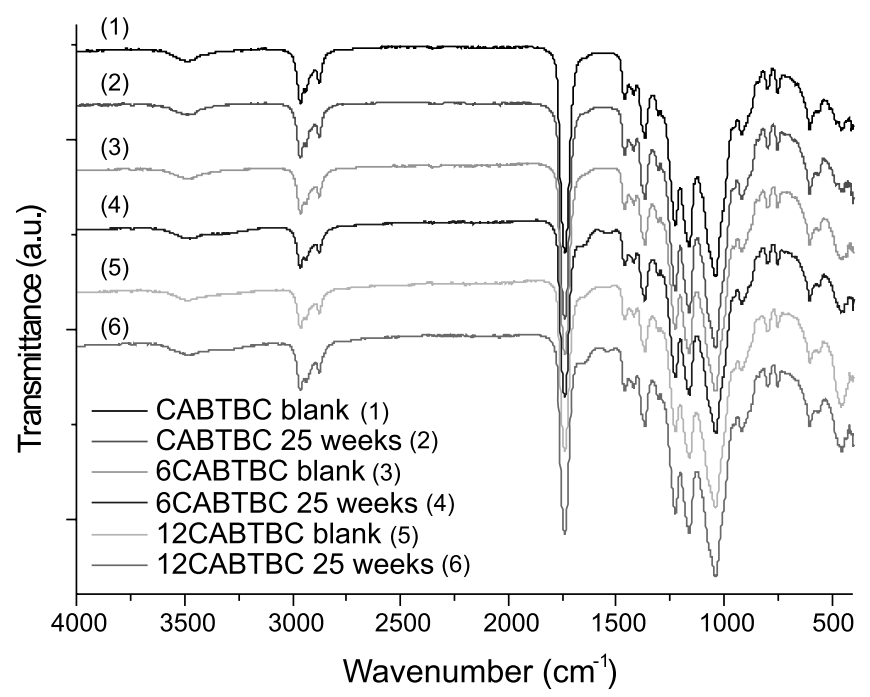

Figure 7. The ATR-FTIR spectra of CABTBC samples before and after the incubation in the sea water

the changes of polymer surface and weight losses. The FTIR data are in agreement with other results and confirmed that for the incubation period of 25 weeks the main role in environment degradation of CAB-hybrids play the amount of inorganic phase and type of the plasticizer introduced in the polymer matrix.

Figure 5. The ATR-FTIR spectra of CAB samples before and after the incubation in the sea water 


\section{CONCLUSIONS}

The results of this study indicate that the organic-inorganic hybrids based on cellulose acetate butyrate are more susceptible to degradation in natural sea water environment than the pure polymer. The higher the amount of silica incorporated into the CAB with the DEP plasticizer, the higher degradability of the samples. The experiment also showed a synergistic effect of the applied plasticizer on the degradation rate of the $\mathrm{CAB} /$ silica hybrids. The $\mathrm{CAB} /$ silica hybrids with diethyl phthalate were degraded faster than the hybrids with tributyl citrate due to the higher brittleness of those samples.

\section{LITERATURE CITED}

1. Klemm, D., Heublein, B., Fink, H.P. \& Bohn, A. (2005). Cellulose: fascinating biopolymer and sustainable raw material. Angew. Chem. Int. Ed. 44, 3358-3393. DOI: 10.1002/ anie.200460587.

2. Edgar, K.J., Buchanan Ch.M., Debenham J.S., Rundquist P.A., Seiler B.D., Shelton M.C. \& Tindall D. (2001). Advances in cellulose ester performance and application, Prog. Polym. Sci. 26, 1605-1688. DOI: 10.1016/S0079-6700(01)00027-2.

3. Lee, S.H., Yoshioka, M. \& Shiraishi, N. (2000). Polymer Blend of Cellulose Acetate Butyrate and Aliphatic Polyestercarbonate. J. Appl. Polym. Sci. Vol. 77, 2908-2914. DOI: $10.1002 / 1097-4628(20000923)$.

4. Grunert, M. \& Winter, W.T. (2002). Nanocomposites of cellulose acetate butyrate reinforced with cellulose nanocrystals. J. Polym. Environ. 10(1/2), 27-30. DOI: 10.1023/ A:1021065905986.

5. Kosaka, P.M., Kawano, Y., Petri, H.M, Fantini, M.C.A. \& Petri, D.F.S. (2007). Structure and properties of composites of polyethylene or maleated polyethylene and cellulose or cellulose esters. J. Appl. Polym. Sci. Vol. 103, 402-411. DOI: 10.1002/app.24836.

6. Wang, T., Cheng, G., Ma, S., Cai, Z. \& Zhang, L. (2003). Crystallization Behavior, Mechanical Properties, and Environmental Biodegradability of Poly( -hydroxybutyrate)/Cellulose Acetate Butyrate Blends. J. Appl. Polym. Sci. Vol. 89, 2003, 2116-2122. DOI: 10.1002/app.12359.

7. Hofacker, S., Mechtel, M., Mager, M. \& Kraus, H. (2002). Sol-gel: a new tool for coatings chemistry. Prog. Org. Coat. 45, 159-164. DOI: 10.1016/S0300-9440(02)00045-0.

8. Sforca, M.L., Yoshida, I.V.P. \& Nunes, S.P. (1999). Organic-inorganic membranes prepared from polyether diamine and epoxy silane. J. Memebrane Sci. 159, 197-207. DOI: 10.1016/S0376-7388(99)00059-9.

9. Kickelbick, G. (2003). Concepts for the incorporation of inorganic building blocks into organic polymers on a nanoscale. Prog. Polym. Sci. 28, 83-114. DOI: 10.1016/S00796700(02)00019-9.

10. Schubert, U. (1994). Catalysts made of organic-inorganic hybrid materials. New J. Chem. 18, 1049-1058.

11. Kickelbick, G. (2007). Hybrid Materials. Synthesis, Characterization, and Applications, Weinheim, WILEY-VCH Verlag $\mathrm{GmbH} \&$ Co. KGaA.

12. Chiang, C.L., Ma, C.C.M., Wu, D.L. \& Kuan, H.C. (2003). Preparation, Characterization, and Properties of Novolac-Type Phenolic/SiO $\mathrm{Si}_{2}$ Hybrid Organic-Inorganic Nanocomposite Materials by Sol-Gel Method J. Polym. Sci. Part A Polym. Chem. 41, 905-913. DOI: 10.1002/pola.10624.

13. Tamaki, R. \& Chujo, Y. (1998). Synthesis of Poly(vinyl alcohol)/Silica Gel Polymer Hybrids by In-Situ Hydrolysis Method. Appl. Organometal. Chem. 12, 755-762. DOI: 10.1002/ (S ICI ) 1099-0739(199810/11)12:10/11<755:AID AOC783>3.0.CO;2-A.
14. Babooram, K., Francis, B., Bissessur, R. \& Narain, R. (2008). Synthesis and characterization of novel (amide-imide)silica composites by the sol-gel process. Comp. Sci. Tech. 68, 617-624. DOI: 10.1016/j.compscitech.2007.10.012.

15. Yano, S., Iwata, K. \& Kurita, K. (1998). Physical properties and structure of organic-inorganic hybrid materials produced by sol-gel process. Mater. Sci. Engng. C 6, 75-90. DOI: 10.1016/S0928-4931(98)00043-5.

16. Brinker, C.J. \& Scherer, G.W. (1990). Sol-Gel Science, San Diego, Academic Press Inc.

17. Jakubiak, P. \& Foltynowicz, Z. (2006). Patent Pending No. P-380939 (2006). Polish Patent Office.

18. Wojciechowska, P. \& Foltynowicz, Z. (2009). Synthesis of organic-inorganic hybrids based on cellulose acetate butyrate. Polimery. 11-12, 845-848.

19. Lenz, R.W. (1993). Biodegradable polymers. In N.A. Peppas \& R.S. Langer (Eds.), Advances in polymer science: biopolymers I. (pp. 4-39). Berlin, Germany: Springer-Verlag.

20. Rutkowska, M., Krasowska, K., Heimowska, A. \& Kowalczuk, M. (2001). In E. Chiellini et al. (Eds.), Biorelated polymers: sustainable polymer science and technology, New York: Kluwer Academic, Plenum Publishers.

21. Rutkowska, M. \& Heimowska, A. (2008). Degradability of natural polymers in sea water. Polimery. 11-12, 854-864 (in Polish).

22. Rutkowska, M., Heimowska, A., Krasowska, K. \& Janik, H. (2002). Biodegradability of Polyethylene Starch Blends in Sea Water. Pol. J. Environ. Stud. 11(3), 267-274. 